\title{
Misconceptions about subarachnoid anesthesia block in the Egyptian female patients; causes and management
}

\author{
Hani I. Taman, Mohammed A. Hegazy \\ Department of Anesthesia \& Intensive Care, Mansoura University Hospitals, F1, 60, El Gomhoria Street, Qism 2, Mansoura \\ 35516, Dakahleya Governorate, Egypt. \\ Correspondence: Mohammed Adel Hegazy, MD, EDAIC \{ORCID-0000-0002-2482-718X; \\ E-mail: dr_mhegazy7000@yahoo.com; Tel: +201002025982
}

\section{Abstract}

Background and aims: Spinal anesthesia (SA) is widely used for many surgeries and when compared to general anesthesia (GA), it has lower rates of complications. However, anxiety or refusal of regional technique in our country is common and multi factorial. This study tried to find the main causes of refusal of SA and to suggest different solutions for the associated anxiety.

Methodology: 160 adult Egyptian female patients (over 18 y of age), ASA II, who were enrolled for elective cesarean delivery were included in this study. During a preoperative visit a questionnaire was given to those who refused SA to enquire about their worries about SA, and to suggest different solutions to relieve the anxiety associated with SA as well as to describe the most frequently associated complications.

Results: Higher rate of SA acceptance was noticed among urban and employed patients with no effect of education on their decision. Fear of post spinal backache was the leading cause $(90.75 \%)$ of refusal in patients, followed by fear of intraoperative pain in $85.83 \%$, while fear of residual paralysis was the least common cause (13.33\%). Sedation was the effective method to overcome anxiety during spinal aesthesia in $56.67 \%$ of patients. PONV represents the most frequent complication associated with SA, in $25.83 \%$ patients.

Conclusion: In conclusion, urban residency and employment status positively affect the decision of SA acceptance, however; educational level has no effect. Post spinal backache and fear of intraoperative pain were the principle causes of SA refusal. Adequate sedation is the most effective method to alleviate anxiety from SA. PONV and hypotension are common unwanted complications of SA.

Key words: Spinal anesthesia; Satisfaction; Cesarean section; Backache; PDPH; Complications, spinal anesthesia

Citation: Taman HI, Hegazy MA. Misconceptions about subarachnoid anesthesia block in the Egyptian female patients; causes and management. Anaesth. pain \& intensive care 2020;24(3):284-290

Received: 19 August 2019, Reviewed: 21 September 2019, 18 May 2020, Revised: 26 January 2020, Accepted: 18 May 2020

\section{Introduction}

Lumbar puncture is routinely performed by anesthesiologists for many purposes such as delivering local anesthetics into subarachnoid space for abdominal and lower limbs surgery, cesarean delivery, obtaining CSF samples for chemotherapeutic drugs.1 Compared to general anesthesia (GA), spinal anesthesia (SA) has lower rates of venous thromboembolism, myocardial infarction, less requirement of postoperative analgesia, decreased sympathetic response to surgical stimulation, and several other complications. 2 However, complications occurring during or after anesthesia and discomfort from the procedure or positioning for neuraxial block may be linked to fear of SA.

The primary aim of this study was to assess the main causes for refusal by parturients for SA for cesarean section. Secondary outcomes were to investigate the most effective method for anxiety management during SA, degree of satisfaction after having SA and the common unwanted complications associated with SA in this group.

\section{Methodology}

This prospective study was carried out at the Department of Anesthesiology, Mansoura University Main Hospital. from May, 2018 to August 2019, after 
obtaining the approval from Ethics Review Committee of Mansoura Faculty of Medicine and informed consent of all patients.

A total of 160 adult Egyptian female parturients (ages over 18 y), ASA II, who were submitted for elective surgical cesarean section were included in this study. Patient refusal, patients with history of associated neurological disorder (seizures, spinal anomaly, low back pain, and prior back surgery), skin infection at puncture site, sepsis, drug allergies and coagulation defects, were excluded from the study. Pregnant females with hypertensive disorder, emergency cesarean sections due to fetal distress or other causes, were also excluded.

During pre-anesthetic assessment visit, patients were asked if they prefer to have GA or SA for their prospective surgery. Those patients who agreed to have SA were excluded from the survey. Others who refused having SA were given a survey to investigate causes of misconceptions and thus refusing SA.

The questionnaire was based upon some common beliefs held by patients who had had SA previously, and from previous studies. We collected the most common items and each one was tested for validity and reliability through a pilot study. ${ }^{5,6,7}$ The questions in this survey included a series of closed statements answered "Yes" or "No". The items of questionnaire are shown in Box 1. The patients were asked to choose one or more causes of refusal of SA.

\begin{tabular}{|ll|}
\hline \multicolumn{2}{|c|}{ Box 1: Survey questions } \\
1- & Advice from relatives \\
2- & Fear of needle prick pain \\
3- & Fear of residual lower limb numbness \\
4- & Fear of intraoperative pain \\
5- & Fear of performer \\
6- & Fear of residual paralysis \\
7- & Post-spinal backache \\
8- & Post dural puncture headache (PDPH) \\
9- & Unable to explain \\
\hline
\end{tabular}

After completing the questionnaire, a detailed explanation of subarachnoid anesthetic block procedure and the principles, including all anatomical, physiological and pharmacological facts, was shared with the patient. The steps of the anesthetic technique were explained in simple words. Finally, possible complications and the appropriate methods to deal with and how to react if she felt discomfort or anxiety during the surgery.
Then the patients were asked if they had changed their misconceptions about SA and if they would proceed with regional anesthesia. Patients who accepted SA, were investigated for satisfaction after SA and if they would opt for SA in their subsequent surgery.

The anesthesiologists were asked for their opinion about the most effective technique to alleviate their patients' anxiety. We defined a 4-step ladder approach (Box 2).

Box 2: 4 step approach - Anesthesiologists

1- Intraoperative assurance and friendly communication

2- Distraction techniques (listening to music, deep breathing and meditation),

3- Giving sedation (3-5 mg midazolam)

4- Administration of GA.

Preloading with normal saline, 500 to $1,000 \mathrm{ml}$ was done to prevent hypotension and SA was administered using $0.5 \%$ heavy bupivacaine.

On the day after surgery, trained anesthesia personnel visited all patients and collected postoperative data, including patient satisfaction score. Postoperative nausea and vomiting (PONV), urinary retention, postoperative backache, $\mathrm{PDPH}$, and transient neurologic symptom (TNS).

Sample size

Sample size of this study was calculated using PS software for Windows version 10 according to differences in number of backache as a cause of refusal in the pilot study of patients. It revealed 129 patients to obtain power of about $80 \%$. We increased the number of patients up to 160 patients to compensate $25 \%$ possible dropouts.

Statistical analysis

Statistical analyses were performed using SPSS software (Version 19.0, SPSS Inc., IL, USA). Data are expressed as mean $\pm \mathrm{SD}$, median (range) or number (\%). Associations of categorical variables with patient refusal were assessed using chi square tests. Effect modifiers were controlled through stratification of age, parity, education status, to see the effect of these on outcomes. $\mathrm{P}<0.05$ was considered statistically significant. Face validity of the used questionnaire was tested by showing the survey to untrained individual to see whether they think all items look suitable or not. Construct validity was tested using SPSS, moment Pearson correlations. Reliability was tested by two 
means; first, during pilot study test-retest reliability; second by using SPSS, Cronbach alpha test Dichotomous question items.

\section{Results}

160 adult pregnant female patients were initially enrolled in this study. 40 patients asked for GA from the start of the study. 120 patients completed the study. Demographic data are presented in (Table 1).

In the current study, post spinal backache was the leading cause of refusal in $(90.75 \%)$ of the studied group, followed by fear of intraoperative pain in $(85.83 \%)$, fear of needle prick pain in $(80.83 \%)$, advice from relatives in $(71.67 \%)$, fear of residual lower limb numbness in $(44.17 \%)$, PDPH in $(25.83 \%)$, unable to explain in $(22.5 \%)$, fear of performer in (15\%) and lastly fear of residual paralysis in $(13.33 \%)$ patients (Figure 2).

Table 1: Demographic data of the overall study population (data presented as mean \pm SD, number (percentage)

\begin{tabular}{|l|l|}
\hline $\begin{array}{c}\text { Patient } \\
\text { characteristics }\end{array}$ & \multicolumn{1}{c|}{ Study group $(\boldsymbol{n}=\mathbf{1 2 0})$} \\
\hline Age (year) & $28.4 \pm 10.13$ \\
\hline Height $(\mathrm{cm})$ & $159.1 \pm 13.8$ \\
\hline Weight $(\mathrm{kg})$ & $76.4 \pm 18.4$ \\
\hline \multirow{2}{*}{ Residency } & Urban: $69(57.5 \%)$ \\
\cline { 2 - 2 } & Rural: $51(42.5 \%)$ \\
\hline \multirow{2}{*}{ Education } & Educated: $94(78.3 \%)$ \\
\cline { 2 - 2 } & Non-educated: $26(21.67 \%)$ \\
\hline \multirow{2}{*}{ Employment } & Employment: $106(88.3 \%)$ \\
\cline { 2 - 2 } & Non-employment:14 (11.67\%) \\
\hline
\end{tabular}

In order to alleviate anxiety, 56.67\% needed sedation, $20 \%$ distraction of attention, $17.5 \%$ explanation, assurance and communication, and only $5.83 \%$ of patients had to be converted to GA to complete the surgery.

Among all of our patients undergoing SA, the level of satisfaction was $76.4 \%$ and those desired to have SA in the future were $56.1 \%$.
Lastly, the most frequent complication was PONV (25.83\%), hypotension (19.66\%), dyspnea (19.17\%), bradycardia (15.17\%), PDPH (13.33\%) backache $(10.83 \%)$ and transient neurological deficit (1\%) in our patients (Figure 3).

\section{Discussion}

Regional anesthesia nowadays, has gained worldwide acceptance, and its physiological effects provide a better outcome for cesarean section, as it provides minimal newborn depression; moreover, GA is associated with significantly high maternal and neonatal morbidity and mortality. ${ }^{9,10}$

In the same way, recent trials describe benefits of SA to be; early cannula removal, early ambulation, early breast-feeding initiation and potential for shorter hospitalization period after cesarean delivery. ${ }^{11}$

However the choice of anesthesia techniques can be expected to differ between countries and cultures. It was noticed that the educational, marital, employment status and location were important factors in determining the choice of anesthesia. ${ }^{12}$ In developed countries, the rate of regional anesthesia is more than $91 \%$ for elective cesarean section and GA is used only in $9 \%$ of cases. ${ }^{13}$ Specifically, in Europe and USA, the rate of GA is as low as $3 \%$ which seems unbelievable in our population. ${ }^{14}$

Anxiety is a common concern about regional anesthesia as a whole and SA specifically. Patients are usually concerned about anesthetic complications. ${ }^{1}$

In the current study, the main causes for anxiety and refusal of SA among our patients were: post spinal backache, followed by acquaintances fear of intraoperative pain, needle prick pain, lower limb numbness, PDPH, fear of performer, residual paralysis and negative advice by the.relatives.

Postoperative backache was commonly associated with dissatisfaction and refusal of spinal blocks. Even though backache may not be directly related to spinal block and related to other causes such as positioning duringsurgery, a tightly applied cast or surgical dressing, surgical trauma, operating time, age, needle type, number of punctures or pre-existing back pain, all these factors make it difficult to diagnose the actual cause of back pain. ${ }^{3,16}$ 


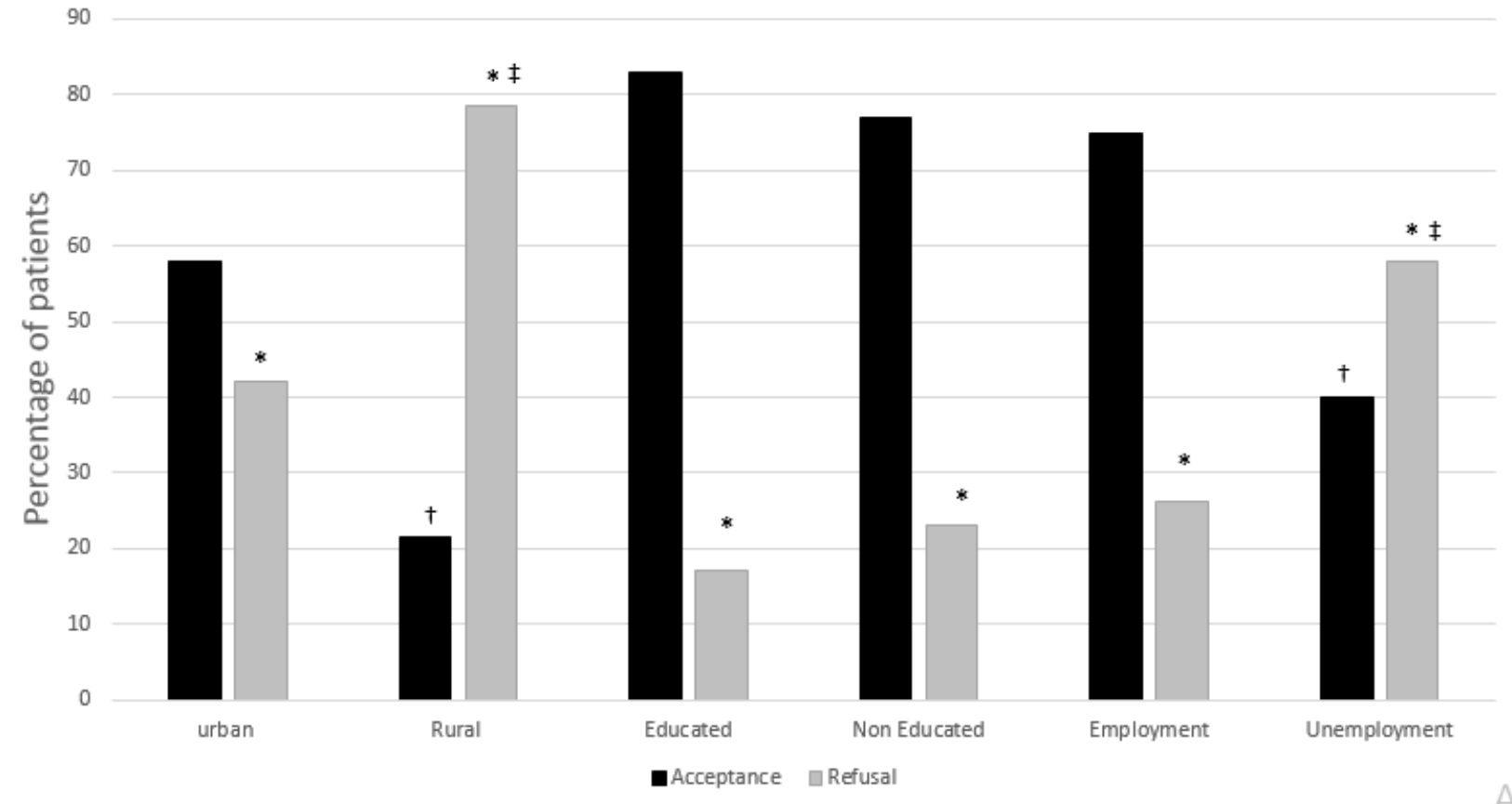

$* \mathrm{p}<0.05$ is considered significant when compared between acceptance and refusal in each group.

$\dagger \mathrm{p}<0.05$ is considered significant when compared between acceptance between each coupled groups.

$\ddagger \mathrm{p}<0.05$ is considered significant when compared between refusal between each coupled groups.

Figure 1: Residency, Educational level and Employment status of all patients grouped according to their acceptance and refusal. Data are expressed as number and percentage



Figure 2: Different causes of misconception and refusal in the studied group 


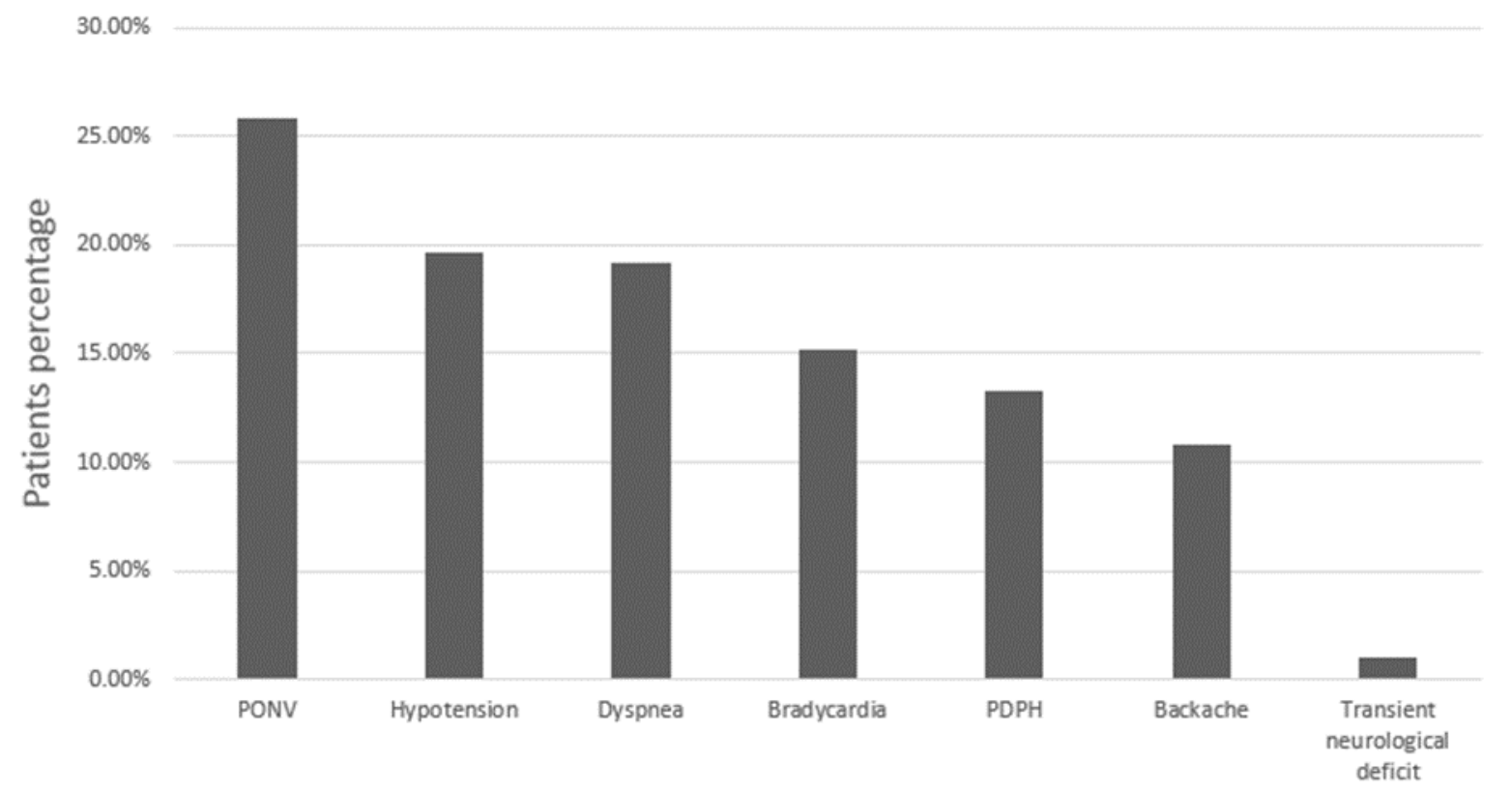

Figure 3: Post-operative complication incidence of the studied group. Data are expressed as number and percentage

In a study by Horlocker TT, post spinal backache was the main cause of refusal in $32(20.1 \%)$ of the studied group, needle prick pain in $62(39 \%)$, peri-operative pain in $14(8.8 \%)$, advice from relatives in $24(15.1 \%)$ and PDPH in 27 (17\%) patients. These results match to a great extent to our study outcome. ${ }^{17}$

Another small study mentioned needle prick pain 23 (5.6\%), post spinal backache pain 107 (26.1\%), headache $29(7.1 \%)$, paralysis $10(2.4 \%)$, numb legs $12(2.4 \%)$, inadequate anesthesia $37(9 \%)$ and bad experience with the anesthetist $32(7.8 \%)$ as the common causes of refusal in women undergoing cesarean section. ${ }^{5,6}$

In another study, the reasons for refusal of SA were as follow: fear of awareness during operation 14 (7\%) and failed SA $2(1 \%)$. Among those obstetrics patients who refused regional anesthesia, $52 \%$ of the fears of all respondents were about paralysis and neurologic disorders, $42 \%$ about peri-operative pain, $38 \%$ about seeing the surgery and hearing the surgical procedure, $33 \%$ were worried of backache and $15 \%$ were afraid of needle. 94 of the 100 patients were convinced to receive regional anesthesia after counseling and explanation with assurance in pre-operative assessment. $^{7}$
Additional reported causes of anxiety may include inaccurate information conveyed to the patient by the acquaintances, the internet, or advertising media. Patients may have been disinformed by television or print stories that often exaggerate the frequency and impact of regional anesthesia complications. ${ }^{18}$

Many different strategies employed to reduce patient anxiety, e.g., talking to the patient and reassurance, giving sedation and distraction techniques (listening to music, deep breathing and meditation), watching the surgery through a screen in the operating room, a printed leaflets, allowing patients to see their nerves while being anesthetized on the ultrasound screen or conversion to GA. ${ }^{19,20}$ Also, viewing an anesthetic video about regional anesthesia pre-operatively has been shown to decrease patients' anxiety. Indeed, a confident, professional and friendly relationship with the patient reduces anxiety. ${ }^{21}$

In our study sedative administration was the most effective method to alleviate anxiety during SA, $56.67 \%$ of the studied patients received sedation at the start of the surgery, and $20 \%$ after surgery started. Assurance and distraction of attention was successful in $17.5 \%$ of patients and 5.83 needed GA to complete the surgery. 
It is not easy to confirm the variables related to patient satisfaction. Side effects, such as postoperative backache, inadvertent mistakes, and unskillful techniques, can negatively affect patient perspective about SA. ${ }^{22}$

In our study, the level of satisfaction and future acceptability of SA was quite high, and matched the majority of the earlier satisfaction studies. ${ }^{23}$ However, the rate of SA rejection was relatively high, compared to other studies. Choi et al. reported 31 out of 194 patients (16\%) would reject receiving SA if they had a chance to have it again. ${ }^{3}$ is well known that dissatisfaction after SA is related to repeated attempts of spinal block, pain during spinal block, inadequate analgesia and post-operative urinary retention. ${ }^{24}$

In the current study, the most frequent complications were PONV, hypotension, dyspnea, bradycardia, PDPH, backache and transient neurological deficit in that order. These are completely different from the main cause reported by Bhatt Arai et al. in which it was prolonged immobility of lower limbs. ${ }^{25}$

\section{Limitations of the study}

The current study investigated the main cause of refusal of SA among a single cohort of females undergoing elective cesarean section. A broad based study, also including other categories of patients, may add to the strength of the study. Also analysis of refusal causes based on social groups my help to obscure the roots of SA refusal problem among population.

\section{Conclusion}

In conclusion, spinal anesthesia acceptance is higher among urban and employed female patients for cesarean sections. Education status has no Effect. Post spinal backache and fear of intraoperative pain were principle causes of spinal anesthesia refusal, followed by fear of needle prick pain, residual lower limb numbness or paralysis and post dural puncture headache. Sedation is useful to alleviate anxiety and increase satisfaction among those patients and needs to be used liberally.

\section{Conflict of interest}

Nil declared by the authors.

\section{Authors' contribution}

HIT: Study design, data analysis, editing

MAH: Dara collection, manuscript writing

\section{References}

1. Jayaraman L, Sethi N, Malhotra S, Sood J. Long length spinal needle in obese patients. Internet $\mathrm{J}$ Anesthesiol. 2008;19(1). [Free Full Text]

2. Gudin MT, López-Vicente R, Ortigosa E, Cascante MD, Molina CG, Martin S. Neuraxial blockade: subarachnoid anesthesia. Essentials Regional Anesth. 2018;213-232. DOI: 10.1007/978-3-31974838-2_11

3. Choi JG, In JY, Shin HI. Analysis of factors related to patient refusal of spinal anesthesia. Korean $\mathrm{J}$ Anesthesiol. 2009;56:156-161. [PubMed] DOI: 10.4097/kjae.2009.56.2.156

4. Oh SH, Kim IH, Choi SR, Chung CJ. Causes of patient dissatisfaction with anesthetic care. Korean J Anesthesiol. 2005;48(4):387-392. DOI: 10.4097/kjae.2005.48.4.387

5. Ahmad I, Afsha G. Knowledge and attitudes of Pakistani women towards anesthesia techniques for Caesarea Section. J Pak Med Assoc. 2011;61(4):359362. [PubMed]

6. Dharmalingam TK, Zainuddin NAA. Survey on maternal satisfaction in receiving spinal anesthesia for caesarean section. Malays J Med Sci. 2013;20(3):5155. [PubMed]

7. Kiskira O, Kolotoura A, Papaioannou A, Vassilas N, Anastassiou $E$, Lekkas D. A survey of obstetric patient who refuse regional anesthesia, causes of refusal and the role of the anesthesiologist. Eur J Anaesthesiol. 2012;29:163-164. [Free Full Text]

8. Jenkinson C, Coulter A, Bruster S, Richards N, Chandola T. Patients' experiences and satisfaction with health care: Results of a questionnaire study of specific aspects of care. Qual Saf Health Care. 2002;11(4):335-344. [PubMed] DOI: 10.1136/ahc.11.4.335

9. Muneer MN, Malik S, Kumar N, Anwar S. Causes of refusal for regional anaesthesia in obstetrics patients. Pak J Surg. 2016;32(1),39-43. [Free Full Text]

10. Cools E, Van de Velde M. Incidence, causes and complications of general anesthesia for cesarean section: A 9-year retrospective analysis of a large 
tertiary centre. Acta Anaesthesiologica Belgica. 2018;69(4),217-224. [Free Full Text]

11. Huang $\mathrm{H}$, Wang $\mathrm{H}, \mathrm{He}$ M. Early oral feeding compared with delayed oral feeding after cesarean section: $A$ meta-analysis. J Matern Fetal Neonatal Med. 2016;29(3),423-429. [PubMed] DOI: $\underline{10.3109 / 14767058.2014 .1002765}$

12. Okafor UV, Ezegwui HU, Ekwazi K. Trends of different forms of anesthesia for caesarean section in Southeastern Nigeria. J Obstet Gynaecol. 2009;29:392395. [PubMed] DOI: $10.1080 / 01443610902932390$

13. Minj B, Verma A. Assessment of knowledge and attitudes of women towards anaesthesia techniques for caesarean section. J Adv Med Dent Scie Res 2016;4(6):247-250. [Free Full Text]

14. Halpern SH, Soliman A, Yee J, Angle D, loscovich A. Conversion of epidural labour analgesia to anesthesia for caesarean section: a prospective study of the incidence and

15. determinant failure. $\mathrm{Br} \mathrm{J}$ Anaesth. 2009;102:240-243. [PubMed] DOI: $\underline{10.1093 / \text { bja/aen352 }}$

16. Jaensson $M$, Dahlberg $K$, Nilsson $U$. Factors influencing day surgery patients' quality of postoperative recovery and satisfaction with recovery: A narrative review. Perioper Med. 2019;8(1):3. [PubMed] DOI: 10.1186/s13741-019-0115-1

17. Liu H, Brown M, Sun L, Patel SP, Li J, Cornett EM, et al. Complications and liability related to regional and neuraxial anesthesia. Best Pract Res Clin Anaesthesiol. 2019 Dec;33(4):487-497. [PubMed] DOI: $10.1016 / j . b p a .2019 .07 .007$

18. Horlocker TT, McGregor DG, Matsushige DK, Schroeder DR, Besse JA. A retrospectives review of 4767 consecutive spinal anesthetics: central nervous system complications. Perioperative Outcomes Group. Anesth Analg. 1997;84:578-584. [PubMed] DOI: $10.1097 / 00000539-199703000-00021$

19. Wilson CJ, Mitchelson AJ, Tzeng TH, El-Othmani MM, Saleh J, Vasdev S, et al. Caring for the surgically anxious patient: a review of the interventions and a guide to optimizing surgical outcomes. Am J Surg. 2016 Jul;212(1):151-159. [PubMed] DOI: 10.1016/j.amjsurg.2015.03.023

20. Mohan B, Kumar R, Attri JP, Chatrath V, Bala N. Anesthesiologist's Role in Relieving Patient's Anxiety. Anesth Essays Res. 2017 Apr-Jun;11(2):449-452. [PubMed] DOI: 10.4103/0259-1162.194576

21. Casale M, Sabatino L, Moffa A, Oliveto G, Rinaldi V, Costantino A, et al. Could music minimize discomfort and pain during office-based ENT surgery? Int J Otolaryngol. 2018 Nov 14;2018:6480346. [PubMed] DOI: $\underline{10.1155 / 2018 / 6480346}$

22. Jlala H, French J, Foxall G, Hardman J, Bedforth N. Effect of pre-operative multimedia information on perioperative anxiety in patients undergoing procedures under regional anesthesia. $\mathrm{Br} \mathrm{J}$ Anaesth. 2010;104:369-374. [PubMed] DOI: 10.1093/bja/aeq002

23. Rhee WJ, Chung CJ, Lim YH, Lee KH, Lee SC. Factors in patient dissatisfaction and refusal regarding spinal anesthesia. Korean J Anesthesiol. 2010;59(4):260-264. [PubMed] DOI: 10.1093/bja/aeq002

24. Siddiqi R, Jafri SA. Maternal satisfaction after spinal anesthesia for cesarean deliveries. J Coll Physicians Surg Pak. 2009;19:77-80. [PubMed]

25. Tan DJA, Sultana R, Han NLR, Sia ATH, Sng BL. Investigating determinants for patient satisfaction in

26.

27. women receiving epidural analgesia for labour pain: $A$ retrospective cohort study. BMC Anesthesiol. 2018 May 9;18(1):50. [PubMed] DOI: 10.1186/s12871-018$\underline{0514-8}$

28. Bhattarai B, Rahman TR, Sah BP, Singh SN. Central neural blocks: a quality assessment of anesthesia in gynaecological surgeries. Nepal Med Coll J. 2005;7:93-99. [PubMed 